\title{
COMPORTAMENTO DO FEIJÃO-FRADINHO NA PRIMAVERA-VERÃO NAZONA DA MATA DE MINAS GERAIS ${ }^{1}$
}

\author{
ROGÉRIO FARIA VIEIRA² ${ }^{2}$ CLIBAS VIEIRA ${ }^{3}$ e MARÍLIA TIBERI CALDAS ${ }^{4}$
}

\begin{abstract}
RESUMO - Três experimentos de competição entre genótipos de feijão-fradinho (Vigna unguiculata (L.) Walp.) foram instalados em Coimbra (17 de novembro de 1993), Ponte Nova (19 de novembro de 1993) e Viçosa (1o de dezembro de 1994), municípios da Zona da Mata de Minas Gerais, com o objetivo de avaliar-lhes o comportamento na primavera-verão, nessa região. Foram testados 18 genótipos em 1993 e 10 em 1994. Foi utilizado o delineamento de blocos ao acaso, com três (1993) e quatro (1994) repetições. Os rendimentos variaram de 106 a $2.562 \mathrm{~kg} / \mathrm{ha}$. Em 1993, quando houve veranico nas três primeiras semanas de fevereiro, os rendimentos máximos foram de 1.587 (Coimbra) e $1.438 \mathrm{~kg} / \mathrm{ha}$ (Ponte Nova), obtidos com a linhagem precoce e de porte intermediário IT 85F-2687. Em 1994, quando choveu regularmente até o mês de março, o rendimento máximo $(2.562 \mathrm{~kg} / \mathrm{ha})$ foi alcançado com a linhagem de ciclo tardio e porte semi-ereto IT 85F-899. A mancha-café (Colletotrichum falcatum f. truncata) foi a única doença observada e as linhagens IT 85F-2687, IT 85D-3428-4, IT 83S-818, IT $83 \mathrm{~S}-899$ e IT $86 \mathrm{D}-716$ foram consideradas resistentes. A primeira colheita foi realizada entre $69 \mathrm{e}$ 79 dias após a emergência, e o período de colheita variou de 16 a 62 dias, dependendo do genótipo e do regime de chuvas
\end{abstract}

Termos para indexação: Vigna unguiculata, cultivo de grãos, rendimento, colheita, mancha-café, Colletotrichum falcatum.

\author{
BEHAVIOR OF BLACKEYE COWPEA IN THE SPRING-SUMMER CULTIVATION \\ AT THE ZONA DA MATA AREA OF MINAS GERAIS STATE, BRAZIL
}

\begin{abstract}
Three trials involving genotypes of blackeye sorts of cowpea (Vigna unguiculata (L.) Walp.) were installed in Coimbra (Nov. 17, 1993), Ponte Nova (Nov. 19, 1993), and Viçosa (Dec. st $^{\text {st }}$ 1994), municipalities of the Zona da Mata area of Minas Gerais State, Brazil, in order to study their behavior during the spring-summer period. Yield ranged from 106 to $2,562 \mathrm{~kg} / \mathrm{ha}$. In 1993, when there was a period of three weeks of water deficit in February, maximum yields were 1,587 kg/ha in Coimbra and $1,438 \mathrm{~kg} / \mathrm{ha}$ in Ponte Nova, achieved with the early-maturing and intermediary plant type line IT 87F-2687. In 1994, when rains were regular until March, maximum yield $(2,562 \mathrm{~kg} / \mathrm{ha})$ was achieved with the late-maturing and semierect plant type line IT 85F-899. Brown bloch, caused by Colletotrichum falcatum $\mathrm{f}$. truncata, was the only disease observed. Lines IT 85F-2687, IT 85D-3428-4, IT 83S-818, IT 83S-899, and IT 86D-716 were resistant to the fungus. The first harvest was made between 69 and 79 days after emergence, and the harvest period varied from 16 to 62 days, depending on genotype and rain period.
\end{abstract}

Index terms: Vigna unguiculata, grain crops, yield, harvesting, Colletotrichum falcatum.

\footnotetext{
${ }^{1}$ Aceito para publicação em 21 de julho de 1999.

${ }^{2}$ Eng. Agrôn., Dr., Embrapa/Epamig, Vila Gianetti, 47, CEP 36571-000 Viçosa, MG. E-mail: rfvieira@homenet.com.br

${ }^{3}$ Eng. Agrôn., Dr., Dep. de Fitotecnia, Universidade Federal de Viçosa (UFV), CEP 36571-000 Viçosa MG.

${ }^{4}$ Estudante de Agronomia, UFV.
}

\section{INTRODUÇ̃̃o}

O caupi (Vigna unguiculata (L.) Walp.) representa cerca de $15 \%$ do feijão produzido no Brasil, sendo o Nordeste a principal região produtora (Bevitori et al., 1992). Essa leguminosa também é conhecida 
por feijão-de-corda, feijão-macassar, feijão-de-praia, feijão-miúdo, feijão-fradinho (grãos brancos) e outros nomes.

O caupi pode ser consumido na forma de vagem verde, grão verde e grão seco, além de outras formas de preparo, como o acarajé, por exemplo. Na forma de vagem verde, a colheita é feita quando as vagens estão bem desenvolvidas, mas com pouca fibra. Para o consumo na forma de grão verde, as vagens são colhidas quando começam a maturar. E para produção de grão seco, as vagens são colhidas secas.

A temperatura mais adequada para o desenvolvimento do caupi situa-se na faixa de 20 a $35^{\circ} \mathrm{C}$ (Araújo et al., 1984), superior à mais adequada para o feijãocomum (Andrade, 1998). Portanto, o caupi poderia ser uma cultura mais adaptada que o feijão-comum para o cultivo de primavera-verão (cultivo "das águas") na Zona da Mata de Minas Gerais, principalmente nos municípios de baixa altitude. Em dois experimentos conduzidos na época "das águas" de 1986, no município de Viçosa, o rendimento médio de duas cultivares de caupi (EPACE-6 e CNC 434) foi de 2.522 e $1.681 \mathrm{~kg} / \mathrm{ha}$, enquanto as cultivares de feijãocomum (Fortuna e Milionário) produziram $2.126 \mathrm{e}$ $1.488 \mathrm{~kg} / \mathrm{ha}$, respectivamente (Vieira, 1989). Vale ressaltar que Viçosa está a $640 \mathrm{~m}$ de altitude e que a primavera-verão de 1986 teve temperaturas relati- vamente amenas. É provável que em municípios de baixa altitude e, ou, em anos mais quentes, e com a disponibilidade de cultivares mais adaptadas à região, a vantagem do caupi seja bem maior em relação ao feijão-comum. O caupi pode vir a ser de interesse econômico na Zona da Mata, visto que essa região encontra-se próxima de um grande mercado consumidor de feijão-fradinho, o Rio de Janeiro.

O objetivo deste trabalho foi avaliar o comportamento de cultivares e linhagens de feijão-fradinho de diferentes portes na primavera-verão na Zona da Mata de Minas Gerais.

\section{MATERIAL E MÉTODOS}

Foram conduzidos três experimentos de competição de linhagens e cultivares de feijão-fradinho, em três municípios da Zona da Mata de Minas Gerais: Coimbra, Viçosa e Ponte Nova. Em Coimbra e Viçosa foi utilizada área pertencente à Universidade Federal de Viçosa; em Ponte Nova, área da Empresa de Pesquisa Agropecuária de Minas Gerais (Epamig). A altitude desses locais é de aproximadamente 740, 640 e $400 \mathrm{~m}$, e os experimentos foram instalados em 17/11/1993, 19/11/1993 e 1o/12/1994, respectivamente. As temperaturas médias e a precipitação que ocorreram durante a condução dos experimentos são apresentadas na Tabela 1 .

TABELA 1. Temperaturas $\left({ }^{\circ} \mathrm{C}\right)$ máximas e mínimas e precipitação $(\mathrm{mm})$ verificadas durante a condução dos experimentos em Coimbra, Viçosa e Ponte Nova (MG).

\begin{tabular}{|c|c|c|c|c|c|c|}
\hline Variável & Novembro & Dezembro & Janeiro & Fevereiro & Março & Abril \\
\hline & \multicolumn{6}{|c|}{ Coimbra $93 / 94^{1}$} \\
\hline Temp. máxima média & 29,5 & 27,8 & 27,6 & 31,6 & & \\
\hline Temp. mínima média & 17,6 & 17,7 & 18,7 & 18,3 & & \\
\hline \multirow[t]{2}{*}{ Precipitação } & 93,4 & 219,4 & 332,5 & $28,1^{2}$ & & \\
\hline & \multicolumn{6}{|c|}{ Ponte Nova 93/94 } \\
\hline Temp. máxima média & 31,7 & 30,7 & 31,0 & 34,6 & & \\
\hline Temp. mínima média & 18,7 & 19,5 & 20,4 & 19,0 & & \\
\hline \multirow[t]{2}{*}{ Precipitação } & 141,5 & 223,1 & 319,6 & $42,5^{2}$ & & \\
\hline & \multicolumn{6}{|c|}{ Viçosa 94/95 } \\
\hline Temp. máxima média & & 28,6 & 31,4 & 29,2 & 28,5 & 26,7 \\
\hline Temp. mínima média & & 18,2 & 18,6 & 18,5 & 17,6 & 16,7 \\
\hline Precipitação & & 283,5 & 105,3 & 91,5 & 192,8 & 63,8 \\
\hline
\end{tabular}

${ }^{1}$ Dados obtidos em Viçosa, que dista cerca de $20 \mathrm{~km}$ da estação experimental de Coimbra.

2 Concentrada na última semana do mês. 
Foi utilizado o delineamento de blocos ao acaso, com três repetições, nos experimentos instalados em 1993, e quatro, em 1994. Cada parcela constou de quatro fileiras de $5 \mathrm{~m}$ de comprimento, espaçadas de $0,75 \mathrm{~m}$ (1993) ou 0,70 m (1994). Em 1993, foram distribuídas 11 sementes por metro de sulco; em 1994, 20 sementes por metro. Neste último ano, foi realizado desbaste para deixar 8 a 10 plantas por metro, aos 20 dias após a emergência (DAE). $\mathrm{Na}$ colheita, foram eliminadas as duas fileiras laterais mais $0,5 \mathrm{~m}$ das cabeceiras das fileiras centrais. Portanto, a área útil foi de $6,0 \mathrm{~m}^{2}$ em 1993 e de 5,6 m² em 1994

As cultivares e linhagens testadas constam nas Tabelas 2,3 e 4 . As linhagens com iniciais IT e NI originaram-se do International Institute of Tropical Agriculture (IITA) As com iniciais CNC foram obtidas na Embrapa-Centro Nacional de Pesquisa de Arroz e Feijão (CNPAF). As cultivares EPAMIG-1 e EPAMIG-2 foram obtidas no comércio, nos EUA e na Itália, respectivamente. Em 1993, foram testadas 18 linhagens e cultivares das quais se tinham sementes suficientes para os experimentos. Ao lado do experimento de Coimbra foi feita multiplicação e avaliação visual de outras 20 linhagens e cultivares. Assim, em 1994, foram utilizadas as cinco linhagens e cultivares mais produtivas em 1993 e as quatro linhagens multiplicadas que apresentaram mais vagens por planta e resistência à mancha-café (Colletotrichum falcatum $\mathrm{f}$. truncata). Ademais, foi incluída a cultivar EPAMIG-2 por causa da ótima qualidade dos grãos (brancos-leite graúdos com mancha preta ao redor do hilo).

$\mathrm{Na}$ adubação básica foram utilizados $600 \mathrm{~kg} / \mathrm{ha}$ do formulado 4-14-8 (N-P $\left.\mathrm{O}_{5}-\mathrm{K}_{2} \mathrm{O}\right)$. Em torno de 30 DAE, foi realizada uma adubação de cobertura com sulfato de amônio (33 kg/ha de N). O controle de plantas daninhas foi feito com enxada durante a fase inicial de desenvolvimento das plantas e, quando necessário, manualmente, quando as plantas já estavam bem desenvolvidas. Na fase vegetativa das plantas foi utilizado inseticida para o controle de pragas, principalmente da vaquinha (Cerotoma arcuata), quando necessário

Em 1993, foram realizadas as seguintes avaliações: porte da planta, intensidade de doença, estande final, rendimento de grãos secos, aspecto comercial dos grãos e peso de 100 grãos. Em 1994, foram avaliados também o comprimento da vagem, o número de vagens por planta e o número de sementes por vagem. Quanto ao porte de planta, as linhagens e cultivares foram classificadas nos seguintes grupos: ereta, semi-ereta, intermediária e semi-ramadora (Araújo et al., 1984). A intensidade de doença foi avaliada com base na seguinte escala arbitrária: 1 - sem sintoma da doença; 3 - leve; 5 - moderada; 7 - severa; e 9 - muito severa. Em 1993, a avaliação de doenças foi realizada antes da primeira colheita e, em 1994, aos 81 e 91 DAE. O as- pecto comercial dos grãos foi avaliado visualmente, após cada colheita, levando-se em conta manchas e descoloração dos grãos, segundo a seguinte escala arbitrária: 1 - ótimo; 2 - bom; 3 - regular; 4 - ruim; e 5 - péssimo. O comprimento da vagem foi anotado aos $69 \mathrm{DAE}$. Foram medidas 10 vagens em maturação, por parcela. $\mathrm{O}$ número de vagens por planta foi obtido da divisão do número total de vagens colhidas pelo número de plantas na área útil. $\mathrm{O}$ número de sementes por vagem resultou da divisão do número total de sementes por parcela pelo número total de vagens colhidas. Os dados foram submetidos à análise de variância, e as médias foram comparadas pelo teste de Tukey, a 5\% de probabilidade.

\section{RESULTADOS E DISCUSSÃO}

\section{Experimento de Coimbra}

A mancha-café foi a única doença observada. As linhagens IT 85F-2687 e IT 85D-3428-4 não apresentaram sintomas da doença (Tabela 2). Por sua vez, as linhagens IT 85D-3577, NI-3 e IT 85D-3517-2 foram severamente atacadas. Os dados de estande final foram perdidos, mas foi observado no campo bom estande em todas as parcelas. $\mathrm{O}$ rendimento de grãos secos variou de 117 a $1.587 \mathrm{~kg} / \mathrm{ha}$ (Tabela 2). Houve correlação significativa e negativa entre intensidade da mancha-café e rendimento $\left(\mathrm{r}=-0,54^{*}\right)$. As linhagens IT 85F-2687 e IT 85D-3428-4, que não apresentaram sintomas da doença, foram as mais produtivas. Ambas têm porte intermediário e pedúnculo longo, principalmente a IT 85D-3428-4. Esta foi a única linhagem com folhas semilanceoladas; as demais tinham folhas ovaladas ou semi-ovaladas. Alinhagem IT 85F-2687 e a cultivar EPAMIG-1 foram as mais precoces, com mais de $50 \%$ do rendimento total obtido aos 73 DAE (Tabela 2). Seis dias mais tarde, foram colhidos entre $87 \%$ e $93 \%$ do rendimento total das linhagens IT 85D-3428-4, IT 84S-2135, IT 35S-818 e IT $85 \mathrm{D}-3577$, quando $97 \%$ e $95 \%$ do rendimento total das linhagens IT 85F-2687 e EPAMIG-1 já haviam sido colhidos. A produção total da linhagem CNCx 670-10E e $64 \%$ do rendimento da linhagem IT 86D-719 - que apresentaram a menor média de rendimento - foram colhidas aos $89 \mathrm{DAE}$.

Nove linhagens, entre elas a IT 85D-3428-4, apresentaram grãos com aspecto comercial entre bom e ótimo, ou seja, havia poucas manchas e descoloração no tegumento dos grãos. Não houve correlação 
TABELA 2. Porte da planta, intensidade de mancha-café, rendimento, porcentagem do rendimento total obtida em cada colheita, aspecto comercial dos grãos e peso de 100 grãos de introduções de feijãofradinho, em Coimbra, MG, 1993².

\begin{tabular}{|c|c|c|c|c|c|c|c|c|}
\hline \multirow[t]{2}{*}{ Genótipo } & \multirow[t]{2}{*}{ Porte da planta } & \multirow{2}{*}{$\begin{array}{l}\text { Intensidade de } \\
\text { mancha-café }\end{array}$} & \multirow{2}{*}{$\begin{array}{c}\text { Rendimento } \\
(\mathrm{kg} / \mathrm{ha})\end{array}$} & \multicolumn{3}{|c|}{ Porcentagem do rendimento total } & \multirow{2}{*}{$\begin{array}{c}\text { Aspecto } \\
\text { comercial } \\
\text { dos grãos }\end{array}$} & \multirow{2}{*}{$\begin{array}{c}\text { Peso de } \\
100 \text { grãos } \\
\text { (g) }\end{array}$} \\
\hline & & & & $73 \mathrm{DAE}^{3}$ & 79 DAE & $89 \mathrm{DAE}$ & & \\
\hline IT $85 \mathrm{~F}-2687$ & Intermediário & $1,0 \mathrm{~d}$ & $1.587 \mathrm{a}$ & 67 & 30 & 3 & 2,1 abcd & 16,0 abcd \\
\hline IT 85D-3428-4 & Intermediário & $1,0 \mathrm{~d}$ & $1.576 \mathrm{a}$ & 0 & 87 & 13 & $1,4 \mathrm{~d}$ & $16,3 \mathrm{abc}$ \\
\hline EPAMIG-1 & Ereto & $2,7 \mathrm{bcd}$ & $1.104 \mathrm{~b}$ & 51 & 44 & 5 & 2,9abc & $17,3 \mathrm{ab}$ \\
\hline IT 87D-1827 & Intermediário & 4,0abcd & $995 b c$ & 0 & 84 & 16 & $1,9 \mathrm{bcd}$ & $15,7 \mathrm{bcd}$ \\
\hline NI-2 & Intermediário & $2,3 \mathrm{~cd}$ & $900 \mathrm{bcd}$ & 9 & 80 & 11 & $1,8 \mathrm{~cd}$ & $13,3 \mathrm{ef}$ \\
\hline IT $84 \mathrm{~S}-2135$ & Intermediário & $5,7 \mathrm{ab}$ & $899 b c d$ & 0 & 87 & 13 & $1,9 \mathrm{bcd}$ & $13,7 \mathrm{def}$ \\
\hline NI & Intermediário & $2,7 \mathrm{bcd}$ & $871 \mathrm{bcd}$ & 4 & 70 & 26 & $3,0 \mathrm{ab}$ & $14,0 \mathrm{cdef}$ \\
\hline IT 81D-1137 & Intermediário & $3,0 \mathrm{bcd}$ & $829 b c d$ & 0 & 82 & 18 & $1,4 d$ & $14,0 \mathrm{cdef}$ \\
\hline IT $83 \mathrm{~S}-818$ & Semi-ereto & $1,7 \mathrm{~cd}$ & $707 \mathrm{cde}$ & 0 & 93 & 7 & $1,8 \mathrm{~cd}$ & 15,0 bcde \\
\hline IT 81D-994 & Intermediário & 4,0abcd & 699cdef & 0 & 71 & 19 & $3,0 \mathrm{ab}$ & $14,3 \mathrm{cdef}$ \\
\hline IT 86D-1010 & Intermediário & 4,3abcd & 610defg & 0 & 66 & 34 & $2,8 \mathrm{abc}$ & $16,3 \mathrm{abc}$ \\
\hline IT 82D-699 & Intermediário & $5,0 \mathrm{abc}$ & 487efg & 0 & 70 & 30 & $2,0 \mathrm{abcd}$ & $18,3 \mathrm{a}$ \\
\hline IT 85D-3577 & Intermediário & $7,0 \mathrm{a}$ & 408efgh & 0 & 91 & 9 & $2,4 \mathrm{abcd}$ & $14,0 \mathrm{cdef}$ \\
\hline NI-3 & Intermediário & $7,0 \mathrm{a}$ & $402 \mathrm{efgh}$ & 0 & 76 & 24 & 2,2abcd & $16,3 \mathrm{abc}$ \\
\hline IT $85 \mathrm{~F}-2264$ & Intermediário & $5,0 \mathrm{abc}$ & $373 \mathrm{fgh}$ & 0 & 61 & 39 & $2,8 \mathrm{abc}$ & $14,3 \mathrm{cdef}$ \\
\hline IT $85 \mathrm{D}-3517-2$ & Intermediário & $6,7 \mathrm{a}$ & $358 \mathrm{gh}$ & 0 & 78 & 22 & $1,9 \mathrm{bcd}$ & $14,3 \mathrm{cdef}$ \\
\hline IT 86D-719 & Intermediário & $3,0 \mathrm{bcd}$ & $117 \mathrm{~h}$ & 0 & 36 & 64 & $3,1 \mathrm{a}$ & $15,7 \mathrm{bcd}$ \\
\hline CNCx $670-10 \mathrm{E}$ & Semi-ramador & $2,0 \mathrm{~cd}$ & $117 \mathrm{~h}$ & 0 & 0 & 100 & $1,9 \mathrm{bcd}$ & $12,0 \mathrm{f}$ \\
\hline Média & & 3,78 & 724,4 & & & & 2,24 & 15,23 \\
\hline C.V. $(\%)$ & & 28,1 & 14,3 & & & & 16,1 & 5,0 \\
\hline
\end{tabular}

${ }_{1} \mathrm{Na}$ coluna, as médias seguidas de pelo menos uma letra igual não diferem significativamente, a $5 \%$ de probabilidade pelo teste de Tukey

2 1: sem sintoma da doença, 9: muito severa; avaliação feita antes da primeira colheita.

3 DAE: dias após a emergência

4 1: ótimo; 5: péssimo; média da avaliação feita nos grãos provenientes de uma ou duas colheitas

significativa entre intensidade da mancha-café e aspecto comercial dos grãos, indicando não ser a doença a causa das manchas e descolorações dos grãos. O peso de 100 grãos variou de 12,0 a $18,3 \mathrm{~g}$. A cultivar EPAMIG-1 e as linhagens IT 85F-2687, IT 85D-3428-4, IT 86D-1010, IT 82D-699 e NI-3 apresentaram grãos graúdos.

\section{Experimento de Ponte Nova}

A mancha-café foi a única doença observada; a média geral de intensidade da doença foi um pouco inferior à observada no experimento de Coimbra. Novamente, as linhagens IT 85F-2687 e IT 85D-3428-4 não apresentaram sintomas da doença (Tabela 3 ). As linhagens NI-2, IT 83S-818 e CNCx 670-10E, que apresentaram intensidade leve da mancha-café em Coimbra, também não foram atacadas. $\mathrm{O}$ estande final variou de $45.000 \mathrm{a} 65.000 / \mathrm{ha}$. O rendimento de grãos secos variou de 106 a $1.438 \mathrm{~kg} / \mathrm{ha}$ (Tabela 3 ). Desta vez não foi significativa a correlação entre intensidade da mancha-café e rendimento. Novamen- te, a linhagem IT 85F-2687 apresentou a maior média de rendimento, a qual, no entanto, não diferiu significativamente da média da cultivar EPAMIG-1 (porte ereto) e das linhagens IT 85D-3428-4 e IT 83S-818 (esta com porte semi-ereto). As linhagens menos produtivas em Coimbra também apresentaram os menores rendimentos neste experimento. O regime de chuvas foi semelhante nos dois locais, ocorrendo três semanas de veranico entre o final de janeiro e o final de fevereiro. A maturação das vagens ocorreu mais cedo, provavelmente por causa das temperaturas mais altas (Tabela 1) durante a condução do experimento. Aos 69 DAE, apenas cinco linhagens e uma cultivar permitiram a colheita de $50 \%$ ou mais do rendimento total, entre elas as que foram mais precoces em Coimbra: IT 85F-2687 e EPAMIG-1. Noventa por cento ou mais do rendimento total das seis cultivares/linhagens com maior média de rendimento foram obtidos com as colheitas efetuadas até $78 \mathrm{DAE}$. Aos $88 \mathrm{DAE}$, a colheita proporcionou entre $4 \%$ e $33 \%$ do rendimento total, dependendo do genótipo. 
TABELA 3. Intensidade de mancha-café, rendimento, porcentagem do rendimento total obtida em cada colheita, aspecto comercial dos grãos e peso de 100 grãos de introduções de feijão-fradinho, em Ponte Nova, MG, 1993'.

\begin{tabular}{|c|c|c|c|c|c|c|c|}
\hline \multirow[t]{2}{*}{ Genótipo } & \multirow{2}{*}{$\begin{array}{l}\text { Intensidade } \\
\text { de mancha- } \\
\text { café }^{2}\end{array}$} & \multirow{2}{*}{$\begin{array}{c}\text { Rendimento } \\
(\mathrm{kg} / \mathrm{ha})\end{array}$} & \multicolumn{3}{|c|}{ Porcent agem do rendimento total } & \multirow{2}{*}{$\begin{array}{c}\text { Aspecto } \\
\text { comercial dos } \\
\text { grãos }^{4}\end{array}$} & \multirow{2}{*}{$\begin{array}{c}\text { Peso de } \\
100 \text { grãos } \\
\text { (g) }\end{array}$} \\
\hline & & & $69 \mathrm{DAE}^{3}$ & $78 \mathrm{DAE}$ & $88 \mathrm{DAE}$ & & \\
\hline IT $85 \mathrm{~F}-2687$ & $1,0 \mathrm{f}$ & $1.438 \mathrm{a}$ & 73 & 23 & 4 & $1,8 \mathrm{c}$ & $15,0 \mathrm{a}$ \\
\hline EPAMIG-1 & $2,7 \mathrm{cdef}$ & $1.246 \mathrm{ab}$ & 50 & 46 & 4 & $2,8 \mathrm{abc}$ & $15,0 \mathrm{a}$ \\
\hline IT 85D-3428-4 & $1,0 \mathrm{f}$ & $1.027 \mathrm{abc}$ & 44 & 46 & 10 & $1,8 \mathrm{c}$ & $14,0 \mathrm{a}$ \\
\hline IT $83 \mathrm{~S}-818$ & $1,0 \mathrm{f}$ & $1.009 \mathrm{abc}$ & 67 & 26 & 7 & $1,9 \mathrm{c}$ & $13,7 \mathrm{a}$ \\
\hline IT 87D-1827 & $1,7 \mathrm{def}$ & $817 \mathrm{bcd}$ & 57 & 37 & 6 & $1,9 \mathrm{c}$ & $13,3 \mathrm{a}$ \\
\hline IT $85 \mathrm{D}-3577$ & $7,0^{\mathrm{a}}$ & $795 \mathrm{~cd}$ & 51 & 42 & 7 & $2,3 b c$ & $12,7 \mathrm{a}$ \\
\hline NI-2 & $1,0 \mathrm{f}$ & $782 \mathrm{~cd}$ & 44 & 45 & 11 & $2,3 \mathrm{bc}$ & $12,3 \mathrm{a}$ \\
\hline IT $84 \mathrm{~S}-2135$ & $6,3 a b$ & $638 \mathrm{cde}$ & 42 & 33 & 25 & $2,1 b c$ & $12,7 \mathrm{a}$ \\
\hline IT 81D-994 & 2,0def & $601 \mathrm{cde}$ & 29 & 49 & 22 & $2,7 \mathrm{abc}$ & $13,7 \mathrm{a}$ \\
\hline IT 81D-1137 & 2,0def & $558 \mathrm{de}$ & 42 & 42 & 16 & $2,1 b c$ & $12,3 \mathrm{a}$ \\
\hline IT 86D-1010 & $1,3 \mathrm{ef}$ & $518 \mathrm{def}$ & 25 & 54 & 21 & $3,5 \mathrm{a}$ & $13,0 \mathrm{a}$ \\
\hline IT 82D-699 & 4,3abcd & 420def & 34 & 37 & 29 & $2,5 \mathrm{abc}$ & $16,0 \mathrm{a}$ \\
\hline NI & $2,0 \mathrm{def}$ & 418def & 25 & 53 & 22 & $3,5 \mathrm{a}$ & $13,3 \mathrm{a}$ \\
\hline NI-3 & $5,5 \mathrm{abc}$ & $411 \mathrm{def}$ & 23 & 44 & 33 & $2,3 \mathrm{bc}$ & $15,3 \mathrm{a}$ \\
\hline IT $85 \mathrm{D}-3517-2$ & $6,3 \mathrm{ab}$ & 389def & 21 & 51 & 28 & $2,5 \mathrm{abc}$ & $12,3 \mathrm{a}$ \\
\hline IT 85F-2264 & $5,7 \mathrm{ab}$ & 376def & 20 & 64 & 16 & $2,4 \mathrm{bc}$ & $14,0 \mathrm{a}$ \\
\hline IT 86D-719 & $4,0 \mathrm{bcde}$ & $243 \mathrm{ef}$ & 27 & 51 & 22 & $3,1 \mathrm{ab}$ & $16,0 \mathrm{a}$ \\
\hline CNCx 670-10E & $1,0 \mathrm{f}$ & $106 f$ & 16 & 51 & 33 & $3,1 \mathrm{ab}$ & $12,0 \mathrm{a}$ \\
\hline Média & 3,10 & 655,2 & & & & 2,47 & 13,7 \\
\hline C.V. (\%) & 29,6 & 22,0 & & & & 13,5 & 11,6 \\
\hline
\end{tabular}

${ }^{1} \mathrm{Na}$ coluna, as médias seguidas de pelo menos uma letra igual não diferem significativamente, a $5 \%$ de probabilidade pelo teste de Tukey.

2 1: sem sintoma da doença; 9: muito severa; avaliação feita antes da primeira colheita.

${ }^{3}$ DAE: dias após a emergência

4 1: ótimo; 5: péssimo; média da avaliação feita nos grãos provenientes de duas ou três colheitas

AEPAMIG-1 tem qualidade de grãos (branco-leite com manchas pretas ao redor do hilo) melhor que a dos demais, mas é mais suscetível a manchas no tegumento (Tabelas 2 e 4). Novamente, a linhagem IT 85D-3428-4 esteve entre as que apresentaram menos manchas e descolorações nos grãos. Em geral, o peso de 100 grãos foi inferior ao verificado em Coimbra, variando de 12,0 a 16,0 g, sem diferenças significativas.

\section{Experimento de Viçosa}

Novamente, o feijão-fradinho foi atacado pela mancha-café. Aos $81 \mathrm{DAE}$, três linhagens não apresentavam sintoma da doença, mas aos 95 DAE to- das elas foram infectadas (Tabela 4). As linhagens IT 83S-899, IT 86D-716, IT 85D-3428-4, IT 85F-2687 e IT $83 \mathrm{~S}-818$ foram as menos atacadas. As linhagens IT 83S-818, IT 87D-1827, CNC 434 e a cultivar EPAMIG-2 apresentaram as vagens mais compridas, entre 17,0 e 19,2 cm. Essa característica é desejável, pois facilita a colheita manual. O estande final médio foi de 104.810 plantas/ha, quase o dobro do verificado no experimento anterior. Segundo Barreto \& Dynia (1988), a população de plantas do caupi tipo ereto e semi-ramador em cultivos mecanizados pode variar de 71.000 a 142.000 plantas/ha. As linhagens IT 83S-899 (porte semi-ereto) e IT 86D-716 (porte intermediário) foram as mais produtivas, superando $2.200 \mathrm{~kg} / \mathrm{ha}$ (Tabela 4). Ambas têm pedúnculo longo, 


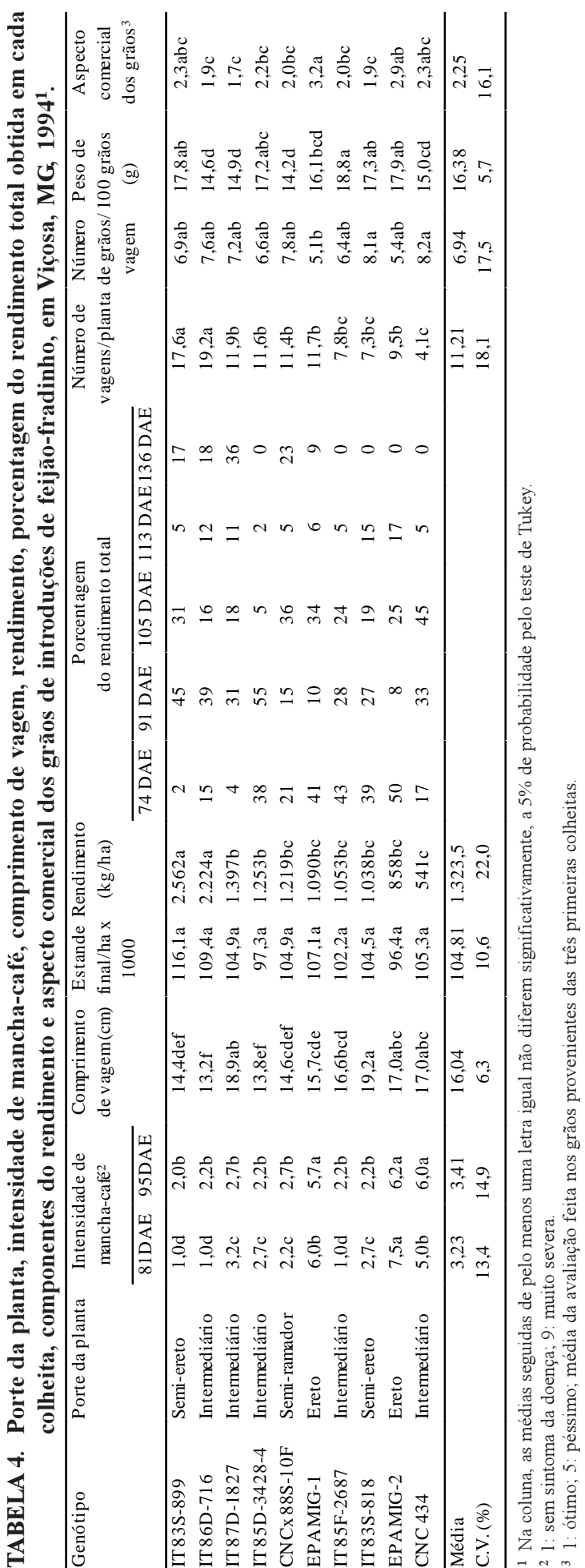

característica que facilita a colheita, principalmente quando mecanizada. Rendimentos dessa magnitude também foram obtidos por Vieira (1989) na época "das águas", em Viçosa, com as cultivares EPACE-6 e CNC 434. Esta última, no entanto, só rendeu $541 \mathrm{~kg} / \mathrm{ha}$ neste experimento. As que sobressaíram no experimento anterior (IT 85F-2687, EPAMIG-1 e IT 85D-3428-4) renderam entre 1.053 e $1.253 \mathrm{~kg} / \mathrm{ha}$, não havendo diferença significativa entre as médias. Houve correlação significativa entre rendimento e intensidade de mancha-café aos $81 \operatorname{DAE}(\mathrm{r}=-0,63 *)$ e aos $95 \mathrm{DAE}(\mathrm{r}=-0,60 *)$. Dos componentes do rendimento, apenas o número de vagens por planta apresentou correlação significativa com o rendimento $\left(\mathrm{r}=0,93^{* *}\right)$.

A colheita teve início aos 74 DAE e terminou entre 113 e 136 DAE (Tabela 4), com duração bem superior à verificada no ano anterior (16 e 19 dias em Coimbra e Ponte Nova, respectivamente). É possível que o alongamento do ciclo do feijão-fradinho em Viçosa tenha sido provocado pelo regime hídrico, que se diferenciou do ano anterior por haver chovido relativamente pouco em janeiro e muito em fevereiro e março (Tabela 1). Em experimento conduzido por Vieira (1989), em Viçosa (semeadura em 11 de novembro), a colheita da cultivar CNC 434 (rendimento de $2.444 \mathrm{~kg} / \mathrm{ha}$ ) teve início aos $84 \mathrm{DAE}(50 \%$ do rendimento total) e terminou aos $111 \mathrm{DAE}$, período de colheita semelhante ao deste experimento. Naquela ocasião choveu regularmente em novembro e dezembro, $145 \mathrm{~mm}$ em janeiro (concentrada na segunda quinzena) e $34 \mathrm{~mm}$ em fevereiro. Novamente, a linhagem IT 85F-2687 e a cultivar EPAMIG-1 estiveram entre as mais precoces, pois mais de $40 \%$ das vagens foram colhidas aos $74 \mathrm{DAE}$, porcentagem só superada pela EPAMIG-2. Considerando as duas primeiras colheitas, a maior porcentagem de grãos colhidos deu-se com a linhagem IT 85D-3428-4 (93\%), seguida da IT 85F-2687 (71\%) e da IT 83S-818 $(66 \%)$. As linhagens mais produtivas foram as mais tardias, concentrando a sua produção entre 91 e 105 DAE, ou seja, foram beneficiadas pelas chuvas de fevereiro e março (Tabela 1).

Os genótipos com grãos mais graúdos (entre 17,2 e 18,8 g) foram: IT 85F-2687, EPAMIG-2, IT 83S-899, IT 83S-818 e IT 85D-3428-4. O aspecto comercial dos grãos variou de quase bom (IT 86D-716, IT 87D-1827 e IT 83S-818) a regular (EPAMIG-1 e EPAMIG-2). Novamente, os grãos da linhagem IT 85D-3428-4 ficaram entre os de melhor aspecto comercial. 
Nos três experimentos, os rendimentos alcançados pelas melhores linhagens foram elevados, visto que no Nordeste o rendimento médio está em torno de $400 \mathrm{~kg} / \mathrm{ha} \mathrm{e}$, nos Estados Unidos, de $600 \mathrm{a}$ $800 \mathrm{~kg} / \mathrm{ha}$ (Bevitori et al., 1992). Portanto, as condições edafoclimáticas da Zona da Mata de Minas Gerais são muito favoráveis ao cultivo do feijãofradinho de porte ereto, semi-ereto e intermediário. Segundo Araújo et al. (1984), as cultivares de porte ramador geralmente se adaptam melhor a solos de baixa fertilidade e a regiões semi-áridas.

\section{CONCLUSÕES}

1. O feijão-fradinho é bem adaptado ao plantio de primavera-verão na Zona da Mata de Minas Gerais.

2. Acultivar EPAMIG-1 e as linhagens IT 85F-2687, IT 85D-3428-4, IT 83S-899 e IT 86D-716 são as mais produtivas.

3. As linhagens IT 85F-2687, IT 85D-3428-4, IT 83S-818, IT 83S-899 e IT 86D-716 são resistentes à mancha-café (Colletotrichum falcatum f. truncata).

4. A primeira colheita é feita entre 69 e 79 dias após a emergência, e o período de colheita se estende de 16 a 62 dias, dependendo do genótipo e do regime hídrico.

\section{REFERÊNCIAS}

ANDRADE, M.J.B. de. Clima e solo. In: VIEIRA, C.; PAULA JÚNIOR, T.J. de; BORÉM, A. (Ed.). Feijão: aspectos gerais e cultura no Estado de Minas. Viçosa : Editora da UFV, 1998. p.83-97.

ARAÚJO, J.P.P. de; RIOS, G.P.; WATT, E.E.; NEVES, B.P. das; FAGERIA, N.K.; OLIVEIRA, I.P. de; GUIMARÃES, C.M.; SILVEIRA FILHO, A. Cultura do caupi, Vigna unguiculata (L.) Walp. descrição e recomendações técnicas de cultivo. Goiânia : Embrapa-CNPAF, 1984. 82p. (Embrapa-CNPAF. Circular Técnica, 18).

BARRETO, P.D.; DYNIA, J.F. Sistema de produção de caupi em monocultura no trópico semi-árido brasileiro. In: ARAÚJO, J.P.P. de; WATT, E.E. (Org.). $\mathbf{O}$ caupi no Brasil. Brasília : IITA/Embrapa, 1988. p.386-404.

BEVITORI, R.; NEVES, B.P. das; RIOS, G.P.; OLIVEIRA, I.P. de; GUAZZELLI, R.J. A cultura do caupi. Informe Agropecuário, Belo Horizonte, v.16, n.174, p.12-20, 1992

VIEIRA, R.F. Comparações de feijões dos gêneros Vigna e Phaseolus com o feijão-comum (Phaseolus vulgaris L.). Viçosa : UFV, 1989. 213p. Tese de Doutorado 